\title{
Article \\ Not All Lectins Are Equally Suitable for Labeling Rodent Vasculature
}

\author{
Roberta Battistella 1,2 ${ }^{1}$, Marios Kritsilis 1,2 1 , Hana Matuskova 1,2,3,4, Douglas Haswell ${ }^{5}$, Anne Xiaoan Cheng ${ }^{5}$, \\ Anja Meissner 1,2,3 (D), Maiken Nedergaard ${ }^{5,6}$ and Iben Lundgaard 1,2,*
}

1 Department of Experimental Medical Science, Faculty of Medicine, Lund University, 22362 Lund, Sweden; roberta.battistella@med.lu.se (R.B.); marios.kritsilis@med.lu.se (M.K.); hana.matuskova@med.lu.se (H.M.); anja.meissner@med.lu.se (A.M.)

2 WCMM Wallenberg Centre for Molecular Medicine, Faculty of Medicine, Lund University, 22362 Lund, Sweden

3 German Center for Neurodegenerative Diseases, 53127 Bonn, Germany

4 Department of Neurology, Division of Vascular Neurology, University Hospital Bonn, 53127 Bonn, Germany

5 Center for Translational Neuromedicine, Department of Neurosurgery, University of Rochester Medical Center, Rochester, NY 14642, USA; douglashaswell@gmail.com (D.H.); anne.cheng@westernu.edu (A.X.C.); Maiken_Nedergaard@urmc.rochester.edu (M.N.)

6 Center for Basic and Translational Neuroscience, Faculty of Health and Medical Sciences, Neurology Department, University of Copenhagen, 2200 Copenhagen, Denmark

* Correspondence: iben.lundgaard@med.lu.se

Citation: Battistella, R.; Kritsilis, M.; Matuskova, H.; Haswell, D.; Cheng A.X.; Meissner, A.; Nedergaard, M.; Lundgaard, I. Not All Lectins Are Equally Suitable for Labeling Rodent Vasculature. Int. J. Mol. Sci. 2021, 22, 11554. https://doi.org/10.3390/ ijms222111554

Academic Editor: Mark Slevin

Received: 31 August 2021

Accepted: 21 October 2021

Published: 26 October 2021

Publisher's Note: MDPI stays neutral with regard to jurisdictional claims in published maps and institutional affiliations.

Copyright: (c) 2021 by the authors. Licensee MDPI, Basel, Switzerland. This article is an open access article distributed under the terms and conditions of the Creative Commons Attribution (CC BY) license (https:// creativecommons.org/licenses/by/ $4.0 /)$.

\begin{abstract}
The vascular system is vital for all tissues and the interest in its visualization spans many fields. A number of different plant-derived lectins are used for detection of vasculature; however, studies performing direct comparison of the labeling efficacy of different lectins and techniques are lacking. In this study, we compared the labeling efficacy of three lectins: Griffonia simplicifolia isolectin B4 (IB4); wheat germ agglutinin (WGA), and Lycopersicon esculentum agglutinin (LEA). The LEA lectin was identified as being far superior to the IB4 and WGA lectins in histological labeling of blood vessels in brain sections. A similar signal-to-noise ratio was achieved with high concentrations of the WGA lectin injected during intracardial perfusion. Lectins were also suitable for labeling vasculature in other tissues, including spinal cord, dura mater, heart, skeletal muscle, kidney, and liver tissues. In uninjured tissues, the LEA lectin was as accurate as the Tie2-eGFP reporter mice and GLUT-1 immunohistochemistry for labeling the cerebral vasculature, validating its specificity and sensitivity. However, in pathological situations, e.g., in stroke, the sensitivity of the LEA lectin decreases dramatically, limiting its applicability in such studies. This work can be used for selecting the type of lectin and labeling method for various tissues.
\end{abstract}

Keywords: lectins; lectin angiography; blood vessels; vascular research; stroke; angiogenesis

\section{Introduction}

The first accurate description of the cardiovascular system dates back to 1628 when the pioneering work of William Harvey revolutionized Galen's theory by centering the movement of blood around the heart as a central pump that pushes blood through a network of conduit vessels, nourishing tissues and organs [1]. In 1661, Marcello Malpighi discovered capillaries as connections between arteries and veins, revising Harvey's model of blood circulation. Since then, many discoveries have improved the complex understanding of the cardiovascular system.

The early stages of cardiovascular development begin in the embryonic mesoderm when angiocysts start forming a primitive endothelial heart tube, preceding the formation of blood vessels through substantial embryonic angiogenesis, followed by pruning and remodeling of the vessels. Although the vasculature develops as one of the first organ systems, reorganization of the vascular system still occurs in adults during different 
physiological and pathological situations, such as the ovarian cycle and the formation of tumors [2]. Furthermore, in the brain, blood vessel angiogenesis and remodeling occur in adult life, for instance, as a response to augmented vascular endothelial growth factor (VEGF) and hypoxia-inducible factor 1 (HIF-1) signaling [3]. Particularly, in response to chronic hypoxia, compensatory vascular mechanisms are activated, leading to an increase in the number, elongation, and enlargement of capillaries [4]. Angiogenesis, and neovascularization constitute a common response to tissue injury, characteristic of several neurological diseases including stroke [5], traumatic brain injury [6], and Parkinson's disease (PD) $[7,8]$. In the aged and vulnerable brain, angiogenesis mechanisms seem to fail [9] and often mark an important risk factor for developing cerebrovascular diseases associated with white matter damage in humans [10]. The vasculature is capable of dynamic adaptation, and this characteristic is of importance to all body tissues. Therefore, it is essential for researchers to understand and investigate the integrity of the vascular system's structure and functionality.

To visualize blood vessels, immunohistochemical techniques targeting endothelial markers such as cluster of differentiation (CD) 31 [11-13] or basement membrane markers such as laminin $[14,15]$ have been widely used. More recently, methods including intravenous injection of fluorescent dyes followed by in vivo two-photon imaging [16-19] or intravenous injection of polymerizing contrast agents followed by ex vivo microCT [20] have been developed.

Interestingly, lectins have been used to label vasculature through immunohistochemical techniques [21-23], as well as direct intravascular delivery [15,24-26]. Indeed, the use of plant-derived lectin proteins for the detection of vasculature dates back to 1982, when it was reported that lectins bind to the luminal part of the capillary endothelium in the mouse pancreas and intestinal mucosa through interactions with sugar residues [27]. As lectins are glycoproteins with a carbohydrate recognition domain, it is not surprising that pretreatment with the specific competitive monosaccharides alone was able to impede lectin binding. Shortly after, lectins were used to label mouse cerebral blood vessels through direct injection in the blood circulation via intracardial perfusion [28], and this approach nowadays is the basis for more sophisticated techniques, including the imaging of vasculature using intravascular lectin perfusion followed by optical clearing and light sheet microscopy [29]. Various lectins have been used as an alternative to the commonly used markers for staining blood vessels in different tissues [15,21,24,26,30,31]. However, studies performing direct comparison of the labeling efficacy of different lectins and their different staining methods as well as studies comparing lectins' specificity towards blood vessels in physiological and pathological conditions are lacking, thus hampering the comparison of results between different studies.

Here, we conducted a comprehensive analysis of the labeling efficacy of three of the most commonly used lectins (Griffonia simplicifolia isolectin B4 (IB4); wheat germ agglutinin (WGA); Lycopersicon esculentum agglutinin (LEA)), and compared the techniques, histological application vs. intracardial perfusion, for labeling blood vessels in different tissues with a focus on the cerebral vasculature. We also applied lectin labeling to a stroke model.

\section{Results}

\subsection{Histological Staining of Cerebral Blood Vessels with the LEA Lectin Gives a Better} Signal-to-Noise Ratio than WGA and IB4 Lectins

The IB4, WGA, and LEA lectins have all been used to either label vasculature upon binding to endothelial cells following intravascular delivery [24-26,30,32] or for labeling blood vessels using immunohistological techniques [15,21-23,33].

Here, we compared the specificity of histological labeling of the mouse vasculature of the most commonly used lectins, WGA, IB4, and LEA (Figure 1). The labeling efficacy was calculated as the ratio of the averaged peak signal at the vascular walls to the background signal (signal-to-noise ratio) of single vessels. In order to determine the lectin concentration with the most appropriate signal-to-noise ratio, we tested different lectin concentrations 
$(5 \mu \mathrm{g} / \mathrm{mL} ; 10 \mu \mathrm{g} / \mathrm{mL} ; 20 \mu \mathrm{g} / \mathrm{mL})$ for WGA, IB4, and LEA staining using $100 \mu \mathrm{m}$ freefloating mouse brain sections (Figure 1A-R).

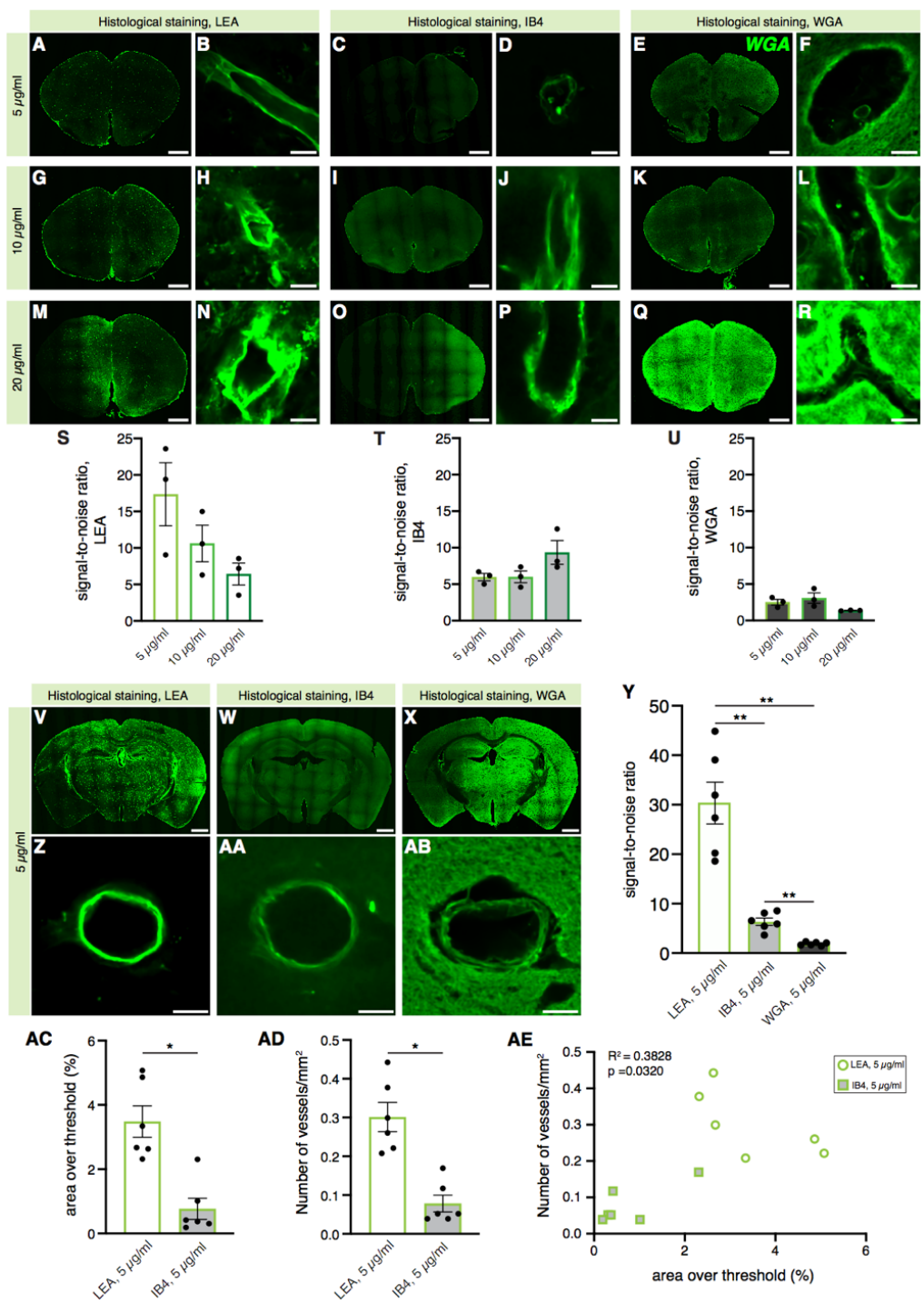

Figure 1. Labeling of blood vessels in free-floating brain sections by lectins Lycopersicon esculentum agglutinin (LEA), Griffonia simplicifolia isolectin B4 (IB4), and wheat germ agglutinin (WGA). (A-R) Representative confocal images of mouse brain sections histologically stained with the LEA, IB4, and WGA lectins at different concentrations. (S-U) Quantification of the signal-to-noise ratio. Each datapoint represents a single vessel; $n=1$. (V-AB) Representative confocal images of (i) $10 \times$ mouse brain sections histologically stained with the LEA, IB4, and WGA lectin solutions at a concentration of $5 \mu \mathrm{g} / \mathrm{mL}(\mathbf{V}, \mathbf{W}, \mathbf{X})$ and (ii) high magnification $(20 \times)$ of the blood vessels $(\mathbf{Z}, \mathbf{A A}, \mathbf{A B})$ used for the quantification of the signal-to-noise ratio in (Y). Three vessels analyzed per animal, $n=6$ mice (repeated measures one-way ANOVA, $p=0.0010$; Tukey's multiple comparisons test: WGA vs. IB4, $p=0.0039$; WGA vs. LEA, $p=0.0025$; IB4 vs. LEA, $p=0.0034$ ). ${ }^{* *}=p<0.01$. (AC-AD) Quantification of the area over the threshold (\%) (AC) and of the number of vessels $/ \mathrm{mm}^{2}$ (AD) labeled by the IB4 and LEA lectins in brain sections. Each datapoint represents the averaged values in one single animal; $n=6$ mice. (AC: Wilcoxon test, $p=0.0312$; AD: Wilcoxon test, $p=0.0312$ ). ${ }^{*}=p<0.05$. (AE) Graph showing the existing correlation between the percentage of the area over the threshold and the number of vessels $/ \mathrm{mm}^{2}$ labeled with the IB4 and LEA lectins in brain sections. Each datapoint represents the averaged values in one single animal; $n=6$ mice (correlation, Pearson coefficient: $\mathrm{R}^{2}=0.3828, p=0.0320$ ). Scale bars: $1000 \mu \mathrm{m}$ for low-magnification images, $10 \mu \mathrm{m}$ for highmagnification images. 
The lowest lectin concentration $(5 \mu \mathrm{g} / \mathrm{mL})$ revealed the lowest background labeling in all lectin stainings (Figure 1S-U) and thus was chosen for the comparison of the LEA, IB4, and WGA signal-to-noise ratios in mouse brain vessels in confocal images at $20 \times$ magnification (Figure $1 \mathrm{~V}-\mathrm{AB}$ ). Our results (Figure $1 \mathrm{Y}$ ) demonstrate that the LEA lectin showed the best efficacy in labeling blood vessels in mouse brain sections and is by far superior to the other commonly used lectins for this type of applications (Figure 1Y; $\mathrm{WGA}=1.882 \pm 0.1366$; IB4 $=6.363 \pm 0.7391$; LEA $=30.34 \pm 4.238$ ). Moreover, the analysis of the LEA's signal-to-noise ratio in labeling longitudinally vs. coronally sectioned vessels (Figure S1A-C) showed a nonsignificant tendency towards higher values in the longitudinally sectioned vessels (signal-to-noise ratio in coronally sectioned vessels: $8.525 \pm 0.6112$; in longitudinally sectioned vessels: $13.66 \pm 1.758)$. On the other hand, the WGA lectin histological staining showed diffuse and unspecific labeling of vascular walls and the parenchyma, resulting in a very high background and a lower signal-to-noise ratio. Compared to the LEA lectin staining, the IB4 lectin covered a lower percentage of the area (Figure 1AC, IB4 $=0.7673 \pm 0.3292 ;$ LEA $=3.484 \pm 0.4896$ ) and labeled overall a lower number of blood vessels (Figure 1AD, IB4 = 78.12 \pm 21.79 ; LEA $=301.6 \pm 37.65$ ), elevating the LEA lectin's value as a useful tool for labeling cerebral blood vessels. When plotted together, the percentage of the area covered by the staining and the number of blood vessels counted per $\mathrm{mm}^{2}$ showed not only a positive correlation (Figure $1 \mathrm{AD}, \mathrm{R}^{2}=0.3828$, $p=0.0320)$, but also the presence of two distinct clusters representing IB4 and LEA staining. We also confirmed that autofluorescence did not alter the LEA lectin's signal-to-noise ratio in comparison with the signal from a tissue that was not labeled with the lectin (Figure S1D-F). Using the same confocal settings (Figure S1D), we could not detect any signal in the 488 spectrum, and only by increasing the settings ten times we were able to detect tissue autofluorescence (Figure S1E).

Taken together, these results indicate that the LEA lectin is preferable over the IB4 and WGA lectins when used to label blood vessels in free-floating brain sections with histological approaches.

\subsection{A Higher Signal-to-Noise Ratio Can Be Achieved by Intracardiac Perfusion of Lectins}

With a molecular weight of $35 \mathrm{kDa}$, the WGA lectin does not cross the blood-brain barrier and can therefore be used to label the cerebral vasculature when administered intravascularly during terminal transcardial perfusion [29], eliminating parenchymal binding. Its relative cost efficiency compared to other lectins, e.g., IB4 and LEA, makes WGA a suitable candidate for methods that require a high volume of the lectin solution, i.e., a direct injection in the mouse bloodstream during terminal transcardial perfusion. We investigated the efficacy of WGA-mediated blood vessel labeling at different concentrations when intracardially perfused and compared it to the histological staining with the LEA lectin on free-floating brain sections (Figure 2A).

Different concentrations of the WGA lectin solution (Figure 2B-H: $5 \mu \mathrm{g} / \mathrm{mL} ; 50 \mu \mathrm{g} / \mathrm{mL}$; $125 \mu \mathrm{g} / \mathrm{mL}$ ) were infused in the different groups of mice, and the signal-to-noise ratio of single vessels was assessed. The quantification showed that the WGA lectin had a concentration-dependent efficacy of staining blood vessels when intracardially perfused, with the best signal-to-noise ratio value in the $125 \mu \mathrm{g} / \mathrm{mL}$ group (Figure 2D, $5 \mu \mathrm{g} / \mathrm{mL}$ $\mathrm{WGA}=9.659 \pm 2.226 ; 50 \mu \mathrm{g} / \mathrm{mL}$ WGA $=25.16 \pm 3.074 ; 125 \mu \mathrm{g} / \mathrm{mL}$ WGA $=44.25 \pm 2.906$ ). 

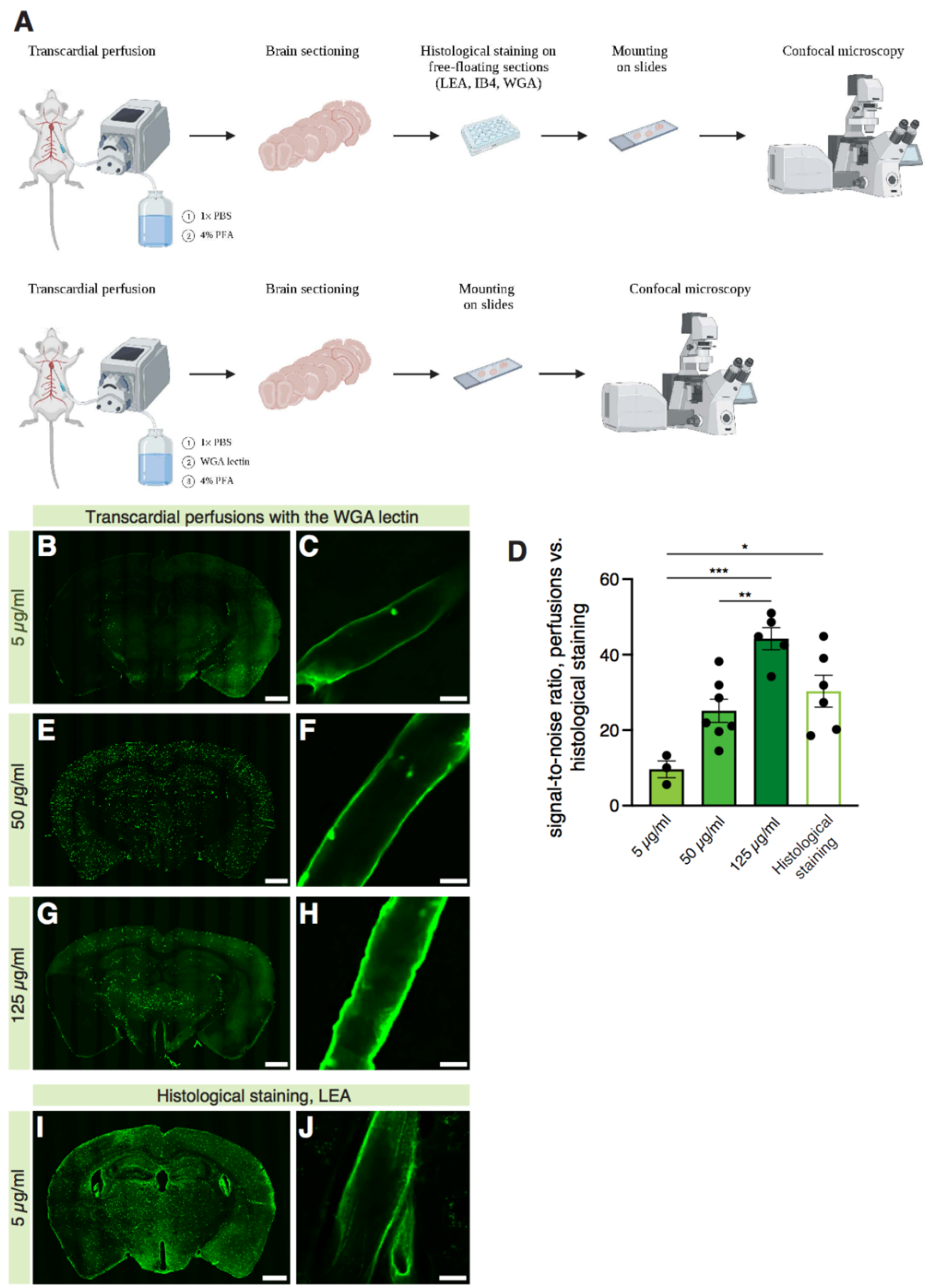

Figure 2. Comparison of different methods to labeling brain vessels with lectins: intravascular WGA delivery during terminal perfusion vs. LEA histological staining on free-floating sections. (A) Schematic drawing summarizing the setup for the experiments comparing the two methods. Created with BioRender. (B-J) Representative $10 \times$ confocal images of brain sections of the mice intracardially perfused with the WGA lectin at a concentration of $5 \mu \mathrm{g} / \mathrm{mL}(\mathbf{B}), 50 \mu \mathrm{g} / \mathrm{mL}$ (E), and $125 \mu \mathrm{g} / \mathrm{mL}(\mathbf{G})$ compared to the ones histologically stained with the LEA lectin (I) and (D) quantification of the signal-to-noise ratio of the vessels stained with different methods (representative confocal $20 \times$-magnified images in $\mathbf{C}, \mathbf{F}, \mathbf{H}, \mathbf{J}$ ). Three vessels analyzed per animal; $n=3$ mice for the $5 \mu \mathrm{g} / \mathrm{mL}$ group, $n=7$ mice for the $50 \mu \mathrm{g} / \mathrm{mL}$ group, $n=5$ mice for the $125 \mu \mathrm{g} / \mathrm{mL}$ group, $n=6$ mice for the LEA histological staining group (one-way ANOVA test, $p=0.0002$; Tukey's multiple comparisons test: $5 \mu \mathrm{g} / \mathrm{mL}$ WGA vs. $125 \mu \mathrm{g} / \mathrm{mL}$ WGA, $p=0.0001 ; 5 \mu \mathrm{g} / \mathrm{mL}$ WGA vs. LEA, $p=0.0112 ; 50 \mu \mathrm{g} / \mathrm{mL}$ WGA vs. $125 \mu \mathrm{g} / \mathrm{mL}$ WGA, $p=0.0047) .{ }^{*}=p<0.05 ;{ }^{* *}=p<0.01 ;{ }^{* * *}=p<0.001$. Scale bars: $1000 \mu \mathrm{m}$ for low-magnification images, $10 \mu \mathrm{m}$ for high-magnification images. 
In order to assess whether perfusion or histological staining would be preferable to achieve the best signal-to-noise ratio, a comparison was made between the two methods. The LEA lectin (Figure 2I-J: $5 \mu \mathrm{g} / \mathrm{mL}$ ) was chosen for the histological staining method since it resulted in the best labeling efficacy on free-floating brain sections in our experimental setup compared to the IB4 and WGA lectins, respectively (Figure 1). The quantification (Figure 2D) showed that intracardiac perfusion of the WGA lectin at high concentrations (i.e., 50 and $125 \mu \mathrm{g} / \mathrm{mL}$ WGA) had a similar signal-to-noise labeling efficacy as the LEA lectin in the histological labeling method $(50 \mu \mathrm{g} / \mathrm{mL}$ WGA $=$ $25.16 \pm 3.074 ; 125 \mu \mathrm{g} / \mathrm{mL}$ WGA $=44.25 \pm 2.906$; $\mathrm{LEA}=30.34 \pm 4.238$ ). These results indicate that although WGA showed the lowest specificity for cerebral blood vessels when applied directly on free-floating brain sections, it can be used for specific labeling of the brain vasculature when applied intravascularly at high concentrations. However, when intracardially injected at low concentrations (i.e., $5 \mu \mathrm{g} / \mathrm{mL}$ ), the WGA lectin shows a significant lower signal-to-noise ratio compared to the LEA lectin's histological staining $(5 \mu \mathrm{g} / \mathrm{mL}$ WGA $=9.659 \pm 2.226 ;$ LEA $=30.34 \pm 4.238)$. In conclusion, several methods for lectin-based labeling of blood vessels are applicable with similar efficacy, enabling the choice of the most suitable method for the experimental design of each individual study.

\subsection{Lectin Is Widely Applicable for Labeling Blood Vessels in Various Tissues}

Next, we tested whether the labeling results obtained with lectins for the cerebral vasculature also applied to other organs. To assess a broad selection of tissues, we investigated labeling of the mouse dura mater, skeletal muscle, kidney, spinal cord, heart, and liver tissues (Figure $3 \mathrm{~A}-\mathrm{X}$ ).

The analysis was performed comparing the lectin staining of the organs of two independent groups of mice. One group was perfused with $1 \times$ PBS followed by $4 \%$ PFA, and the whole-mount dura mater as well as tissue sections of the abovementioned organs were stained with the LEA lectin $(5 \mu \mathrm{g} / \mathrm{mL})$. The second group was intracardially perfused with the WGA lectin $(50 \mu \mathrm{g} / \mathrm{mL})$ to allow labeling of the blood vessels through direct binding of the WGA lectin to the luminal part of the endothelial cells before the organs of interest were harvested.

The labeling efficacy of histological staining with the LEA lectin and intracardial WGA $(50 \mu \mathrm{g} / \mathrm{mL})$ lectin perfusion was comparable in blood vessels of the majority of the organs analyzed, i.e., the dura mater, skeletal muscle, kidney, spinal cord, and heart (Figure 3Y-AC, dura mater: LEA $=8.259 \pm 0.5733,50 \mu \mathrm{g} / \mathrm{mL}$ WGA $=13.65 \pm 5.021$; skeletal muscle: $\mathrm{LEA}=21.85 \pm 4.023,50 \mu \mathrm{g} / \mathrm{mL}$ WGA $=12.60 \pm 4.497$; kidney: LEA $=$ $9.067 \pm 0.6144,50 \mu \mathrm{g} / \mathrm{mL}$ WGA $=10.36 \pm 3.398$; spinal cord: $\mathrm{LEA}=22.45 \pm 3.428$, $50 \mu \mathrm{g} / \mathrm{mL}$ WGA $=14.76 \pm 5.460$; heart: $\mathrm{LEA}=9.404 \pm 0.6159,50 \mu \mathrm{g} / \mathrm{mL}$ WGA $=$ $11.10 \pm 2.336$ ). Thus, both staining methods can be used for the same purpose. In the liver, on the other hand, the LEA lectin staining showed a higher signal-to-noise ratio when compared to the WGA lectin-perfused sections (Figure 3AD, LEA $=12.56 \pm 1.231,50 \mu \mathrm{g} / \mathrm{mL}$ WGA $=5.823 \pm 1.939$ ). This is most likely due to the unique anatomy of blood vessels in the liver defined as "fenestrated" owing to the presence of open pores in the liver sinusoidal endothelial cells [34] which may cause leakage of the WGA lectin solution injected in the blood stream into the liver parenchyma. In the kidney, although the signal-to-noise ratio did not differ between the two labeling methods (Figure 3AA), LEA lectin histological staining (Figure 3L) revealed the characteristic glomeruli structures [35], which were not detectable in kidney sections obtained from the mice intracardially injected with the WGA lectin (Figure 3F), suggesting that the LEA lectin is not filtered in the glomeruli. 

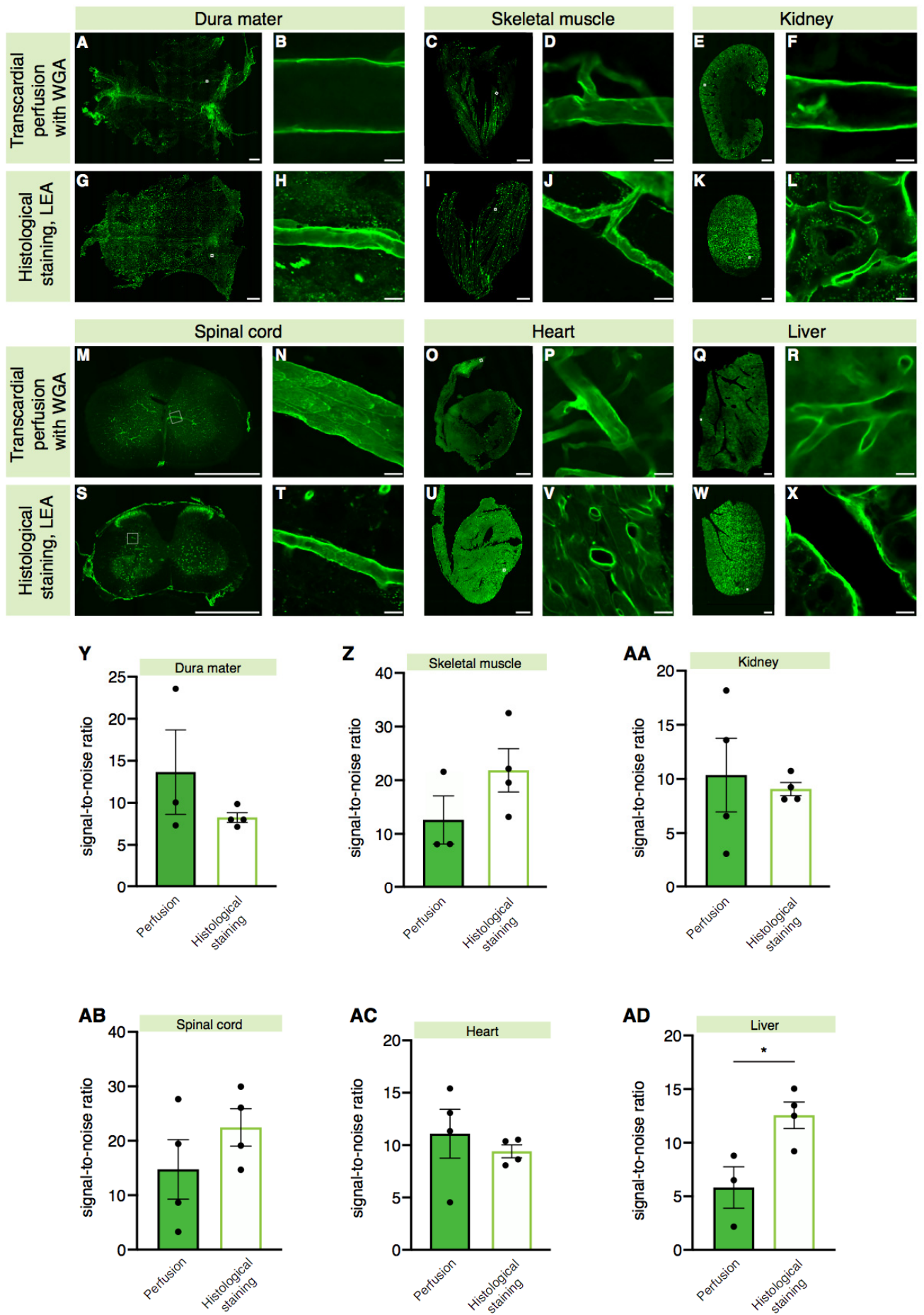

Figure 3. Comparison of different methods of labeling blood vessels in various organs with lectins: WGA intravascular delivery during terminal perfusion vs. LEA histological staining on free-floating sections. (A-X) Representative images of the whole-mount dura mater meninx, skeletal muscle, kidney, spinal cord, heart, and liver tissues of the mice intracardially perfused with the WGA lectin (concentration: $50 \mu \mathrm{g} / \mathrm{mL}$ ) compared with those histologically stained with the LEA lectin. White squares indicate the point where the high magnification images of the blood vessels used for the quantification were acquired from. Scale bars: $1000 \mu \mathrm{m}$ for low magnification images, $10 \mu \mathrm{m}$ for high magnification images. (Y-AD) Quantification of the signal-to-noise ratio values of the two methods in different organs (dura mater: Welch's $t$-test, $p=0.3955$; skeletal muscle: Mann-Whitney U test, $p=0.2286$; Kidney: Welch's $t$-test, $p=0.7319$; spinal cord: unpaired $t$-test, $p=0.2778$; heart: unpaired $t$-test, $p=0.5096$; liver: unpaired $t$-test, $p=0.0272) ; n=3$ to 4 mice for the $50 \mu \mathrm{g} / \mathrm{mL}$ WGA perfusion group and $n=4$ mice for the LEA histological staining group. ${ }^{*}=p<0.05$. 
Interestingly, we detected that both the sagittal and the transverse sinuses in the dura mater were stained with the LEA lectin after histological staining of the tissue (Figure S2B), as well as with the intracardially injected WGA lectin (Figure S2C), showing that lectins label veins efficiently. Lectins can also efficiently label arteries, as shown by the colocalization of the LEA lectin's signal with the alpha smooth muscle actin ( $\alpha$-SMA)-positive vessels (Figure S2D-E).

To assess whether lectins could label lymphatic vessels as well, we used the LEA lectin conjugated to AlexaFluor-647 (Figure S2F) to stain the whole dura of Prox1-eGFP reporter mice [36]. Using confocal imaging and 3D reconstructions thereof, we did not detect colocalization between the lectin and the Prox1-eGFP signal (Figure S2G-J; Supplementary Movie1), suggesting that lectins do not label lymphatic vessels.

In light of our results, albeit seemingly universally applicable, the unique characteristics of the organ of interest used for lectin-based labeling of blood vessels should be considered.

\subsection{Lectin Labeling of Cerebral Blood Vessels Is Equivalent to Reporter Mice and Immunostaining}

We then performed a more detailed investigation of the specificity of lectin labeling of blood vessels by comparing it to immunostaining against glucose transporter-1 (GLUT-1), a protein expressed at the blood-brain barrier site by endothelial cells and astrocytes. GLUT-1 is widely used to label the vasculature in the brain [37]. We also used Tie2-eGFP reporter mice, which carry an endogenous marker of endothelial cells [38]. The Tie2-eGFP reporter mice [39] were intravenously injected with biotinylated lectin $(125 \mu \mathrm{g} / \mathrm{mL})$ and perfused thereafter. Brain sections were processed with $\mathrm{Cy} 3$-conjugated streptavidin and the GLUT-1 antibody (Figure 4A-D').

In each section, blood vessels were identified by the presence of GLUT-1 staining and Tie2-eGFP expression. The presence of lectin co-staining was then quantified for the identified vessels. The application of Cy3-conjugated streptavidin to brain tissue sections from the mice intracardially perfused with biotinylated lectin revealed an extensive pattern of arterioles and capillaries (Figure 4C). The percentage of LEA-stained blood vessels was comparable to that of GLUT-1 labeled vessels (Figure 4E, lectin $=95.75 \pm 4.250$; GLUT-1 = $58.00 \pm 10.72$ ). Our results show that lectin labeling of blood vessels overlaps with GLUT-1 staining in the mouse brain and that the LEA lectin provides reliable labeling of blood vessels even when applied directly to the sectioned tissue. Next, we tested whether lectin sensitivity towards blood vessels could be altered in tissues characterized by endothelia with different characteristics than the brain. Therefore, we tested co-localization of another commonly used marker for endothelial cells, CD31, with LEA in different tissues: the brain as an example of continuous endothelium; the kidney as an example of fenestrated endothelium; and the spleen as an example of discontinuous endothelium. We identified blood vessels in the abovementioned tissues by positivity to CD31, and then we assessed the presence of LEA labeling on the same vessels (Figure 4F-H). Our results showed that $97.43 \pm 1.541 \%$ of the CD31+ vessels were positive for lectin staining in the brain, while the results were $95.83 \pm 2.406 \%$ for the kidney and $92.03 \pm 1.489 \%$ in the spleen, suggesting that lectin sensitivity towards blood vessels does not depend on the intrinsic characteristics of the blood vessels' endothelium (Figure 4I). Moreover, our results showed that while the specificity of the LEA lectin labeling of blood vessels in the brain is $94.62 \pm 1.614$, it decreases considerably in the kidney down to $58.48 \pm 11.19$ as the LEA lectin also labels the glomeruli in this organ (see also Figure 3L). The LEA lectin's specificity was barely assessable in the spleen where the LEA lectin appears to label not only blood vessels, but also the structural reticular meshwork of the spleen, as previously shown to happen in the rat spleen with other lectins [40]. 

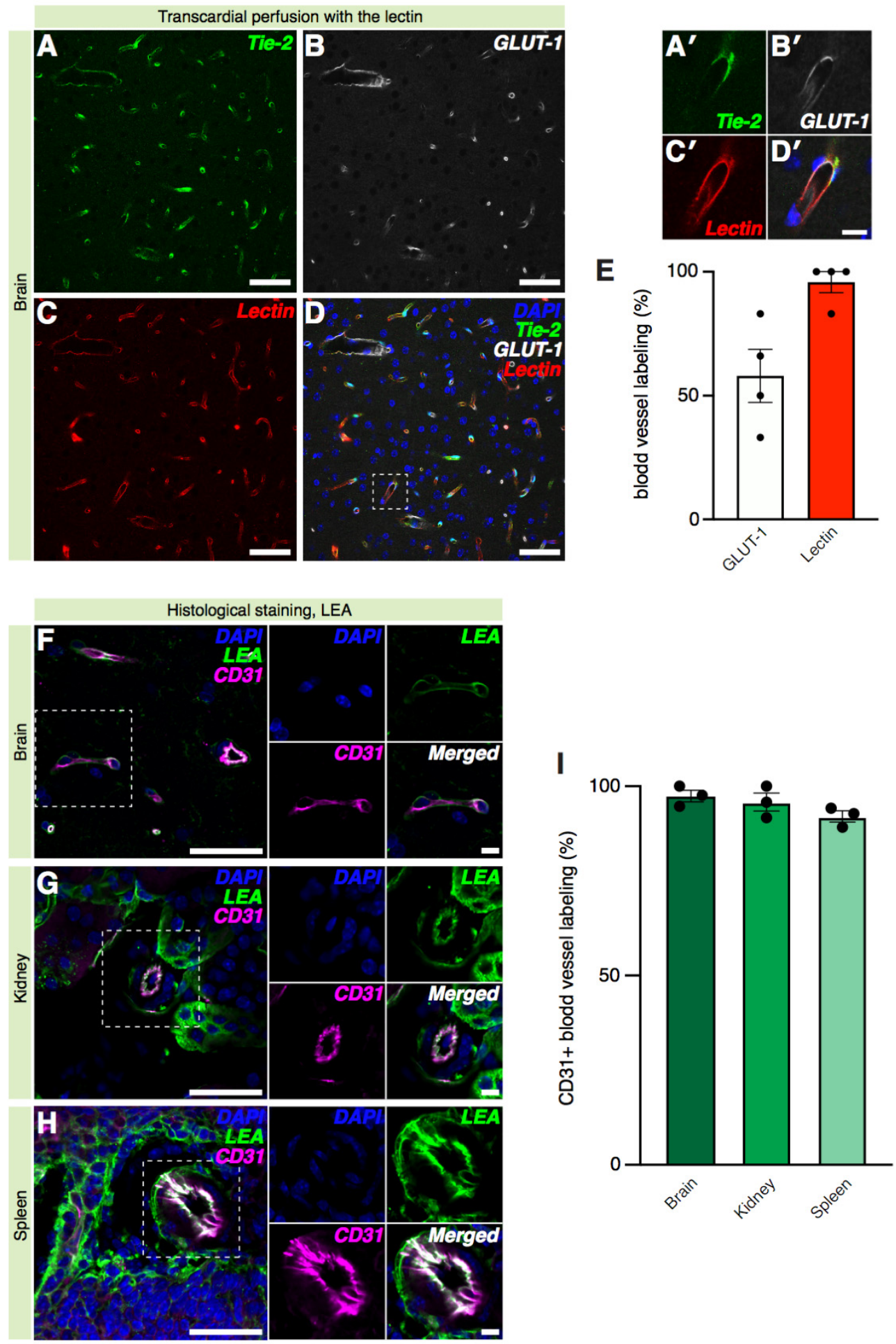

Figure 4. Comparison of lectin labeling of blood vessels in different types of the endothelium with the commonly used blood vessel markers. (A-D) Representative $20 \times$ confocal images of a brain section from a Tie2-eGFP reporter mouse intracardially perfused with the biotinylated lectin and processed with Cy3-conjugated streptavidin and GLUT-1 antibodies. Scale bars: $50 \mu \mathrm{m}$. The white dashed square marks the magnified inset in $\left(\mathbf{A}^{\prime}-\mathbf{D}^{\prime}\right)$. Scale bars: $10 \mu \mathrm{m}$. (E) Quantification of blood vessels labeled (\%) by GLUT-1 and lectin staining; $n=4$ mice (Wilcoxon test, $p=0.2500$ ). (F-H) Representative $20 \times$ confocal images of the brain, kidney, and spleen sections labeled with the CD31 endothelial marker. Scale bars: $50 \mu \mathrm{m}$. White dashed squares mark the magnified insets on the right. Scale bars: $10 \mu \mathrm{m}$. (I) Quantification of CD31+ blood vessels (\%) in the brain, kidney, and spleen tissues that are co-labeled with LEA; $n=3$ mice (one-Way ANOVA, $p=0.1894$ ). 
Therefore, lectin labeling of blood vessels in the brain is as reliable as labeling with commonly used endothelial cell markers. However, the intrinsic structure of some organs, e.g., of the kidney or the spleen, may represent a limitation to the ability of lectin to label specifically blood vessels.

\subsection{LEA Lectin's Specificity for Blood Vessel Labeling Decreases in the Ischemic Brain}

Lastly, we tested whether lectin-based blood vessel labeling may be affected by disease in a mouse model of ischemic stroke where transient occlusion of the middle cerebral artery causes the formation of a necrotic core that is surrounded by a penumbra region (ischemic lesion is indicated with a dashed line in Figure 5A).

The latter is the target of treatment efforts as it is rescuable with adequate strategies $[41,42]$. Regenerative processes in the peri-infarct region include angiogenesis. Since our results presented above suggest sufficient LEA lectin efficacy of histochemically labeling blood vessels in the brain of WT mice, we tested whether a similar efficacy could be achieved to visualize vascularization after transient middle cerebral artery occlusion (tMCAo) in mice.

Brains were harvested 1 and 7 days post-tMCAo and processed for histology. To determine the infarct size, Nissl-stained brain slides (representatives shown in Figure 5A) were quantified. A smaller yet not significantly different lesion size was observed at 7 days post-stroke compared to 1 day post-stroke $(1 \mathrm{~d} \mathrm{tMCAo}=36.10 \pm 6.705 ; 7 \mathrm{~d} \mathrm{tMCAo}=$ $18.00 \pm 4.259 ; p=0.0522$, Figure $5 \mathrm{~B}$ ). In addition to the lesion size, neurological function was assessed in both experimental groups (i.e., the 1-day cohort and the 7-days cohort). The total deficit score was mainly driven by focal deficits in both groups (Figure 5C-D). Longitudinal assessment of neurological function in the 7-days cohort revealed declining general and total deficit score that did not show a significant difference (Figure 5D).

Next, the LEA lectin labeling of blood vessels in the infarct core 1 and 7 days posttMCAo was analyzed and compared with the GLUT-1-immunolabeled blood vessels (Figure 5E-M). Our results showed that $98.78 \pm 1.62 \%$ of the total GLUT-1-labeled blood vessels were also labeled with the LEA lectin, suggesting that sensitivity of the LEA lectin to blood vessels was unaltered by ischemic brain injury. However, we also observed a significant $59.36 \pm 43.12 \%$ reduction of the LEA lectin's specificity towards blood vessels in the infarcted hemisphere 7 days post-tMCAo compared to the naïve condition (Figure 5N, naïve, averaged hemispheres $=73.10 \pm 5.928 ; 7 \mathrm{~d}$ tMCAo $=32.68 \pm 15.51)$. A $29.30 \pm 15.04 \%$ reduction of the LEA lectin's specificity 1 day post-tMCAo was also detected, although not significant (naïve, averaged hemispheres $=73.10 \pm 5.928 ; 1 \mathrm{~d}$ tMCAo $=56.86 \pm 5.410$ ). No significant difference between the control (intact) hemispheres and tissues from the naïve mice was observed (naïve, averaged hemispheres $=73.10 \pm 5.928 ; 1 \mathrm{~d}$ tMCAo $=$ $71.04 \pm 6.8141 ; 7 \mathrm{~d} \mathrm{tMCAo}=81.43 \pm 5.786$ ). The same analysis conducted in the penumbra (Figure S2A-C), showed that the LEA lectin's specificity is also affected in the periinfarct region, showing a significant reduction of $64.20 \pm 9.89 \%$ and $68.94 \pm 18.28 \%$ for 1 and 7 days post-tMCAo, respectively (Figure S2D; left/infarcted hemisphere: naïve = $84.76 \pm 5.031 ; 1 \mathrm{~d}$ tMCAo $=30.93 \pm 3.821 ; 7 \mathrm{~d}$ tMCAo $=26.83 \pm 7.060)$. 

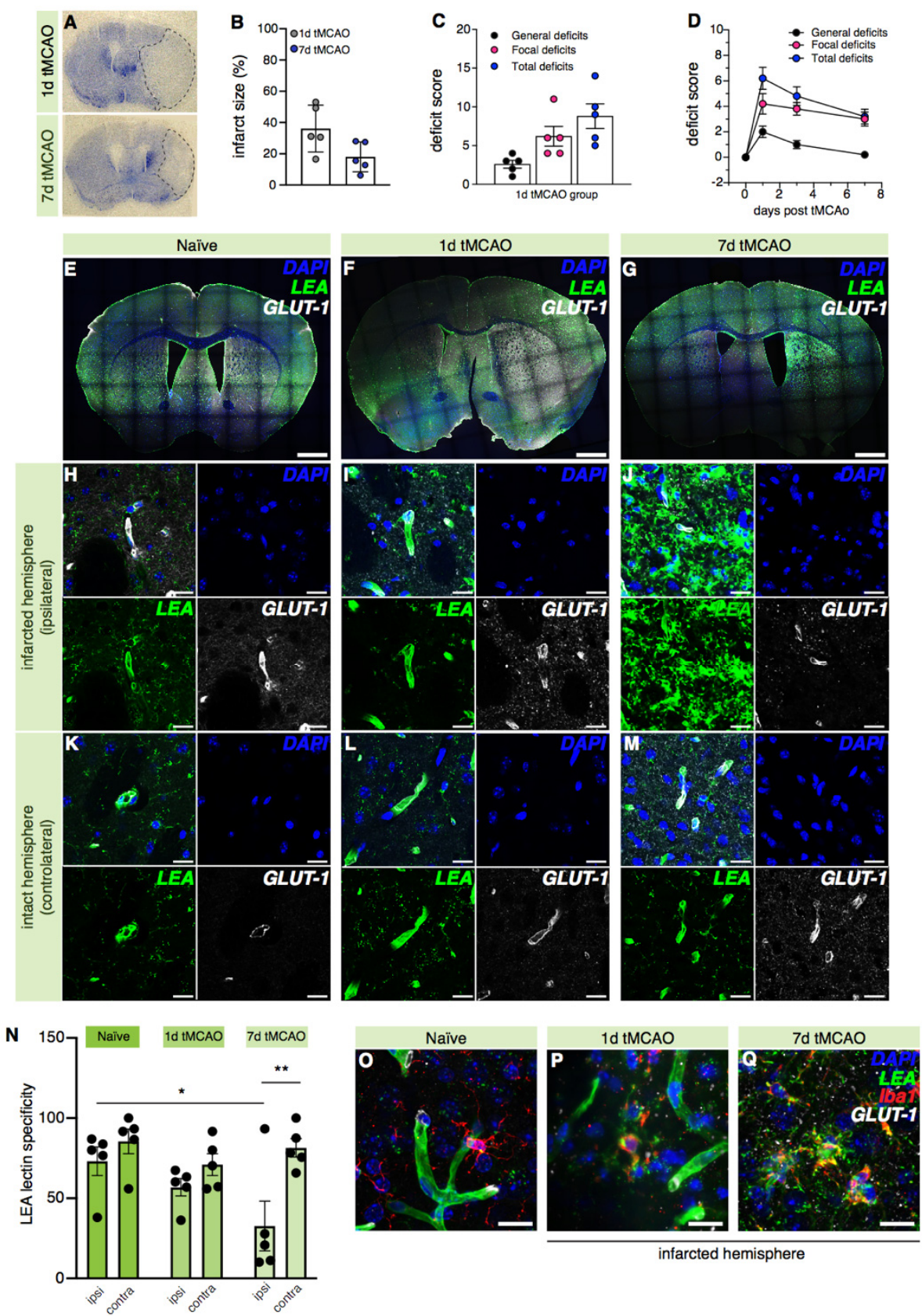

Figure 5. Analysis of the LEA lectin's labeling of blood vessels in the ischemic core of a post-stroke brain. (A) Representative micrograph of the infarcted area (dashed line) in the brain sections of mice 1 and 7 days after transient occlusion of the medial cerebral artery labeled with Nissl staining. Note the infarcted region that appears white. (B) Quantification of the infarct size in mice 1 and 7 days post-tMCAo (unpaired $t$-test, $p=0.0522$ ); $n=5$ mice/group. (C) Neuroscore values in mice 1 day post-tMCAo; $n=5$ mice. (D) Neuroscore in mice 7 days post-tMCAo; $n=5$ mice. (E-M) Representative confocal images of brain sections at $10 \times$ magnification (E-G; scale bars: $1 \mathrm{~mm}$ ) and related blood vessels at $20 \times$ magnification $(\mathbf{H}-\mathbf{M}$; scale bars: $20 \mu \mathrm{m})$ of the naïve, $1 \mathrm{~d}$ tMCAo, and 7d tMCAo mice labeled with the LEA lectin and the GLUT-1 antibody (counterstain: DAPI). (N) Quantification of the LEA lectin specificity (two-way ANOVA test, hemisphere effect, $p=0.0025$; Tukey's multiple comparisons test for the infarcted hemisphere: naïve vs. $1 \mathrm{~d}$ tMCAo, $p=0.4239$; naïve vs. $7 \mathrm{~d}$ tMCAo, $p=0.0112 ; 1 \mathrm{~d}$ tMCAo vs. $7 \mathrm{~d}$ tMCAo, $p=0.1619$; for the intact hemisphere: naïve vs. $1 \mathrm{~d}$ tMCAo, $p=0.5030$; naïve vs. 7d tMCAo, $p=0.9451$; $1 \mathrm{~d}$ tMCAo vs. $7 \mathrm{~d}$ tMCAo, $p=0.6983$; Sidak's multiple comparisons test, infarcted vs. intact hemispheres: naïve, $p=0.6566$; $1 \mathrm{~d}$ tMCAo, $p=0.5601 ; 7 \mathrm{~d}$ tMCAo, $p=0.0034) ; n=5$ mice/group. ${ }^{*}=p<0.05 ;{ }^{* *}=p<0.01$. (O-Q) Representative confocal images of the LEA lectin and Iba1 signal overlapping in the infarcted hemisphere of the $1 \mathrm{~d}$ tMCAo and 7d tMCAo mice compared to the naïve mice. Scale bars: $20 \mu \mathrm{m}$. 
In order to investigate the decreased LEA lectin's specificity in the lesioned hemisphere, we performed counterstaining for the microglia marker ionized calcium-binding adaptor molecule-1 (Iba-1) and the astrocytic marker glial fibrillary acidic protein (GFAP) as both cell types undergo massive activation during brain ischemia $[43,44]$. Our immunostainings showed apparent co-labeling of the LEA lectin and Iba- 1 in the infarcted hemisphere 1 and 7 days post-tMCAo which was absent in the naïve brains (Figure 5O-Q). Interestingly, we did not detect any co-labeling of the LEA lectin with the GFAP astrocytic marker despite apparent astrocytic activation (Figure S2E-G). Thus, our results suggest that the LEA lectin recognizes blood vessels post-stroke; however, it robustly labels other cells in the brain other than endothelial cells, which hampers its suitability as a reliable vessel marker post-stroke.

\section{Discussion}

Lectins have been widely used to label blood vessels in experimental animal models $[27,28]$. However, whilst a systematic comparison of the labeling efficacies of different lectins have been carried out in organs of invertebrate animal models, e.g., in the heart compartments of zebrafish (Danio rerio) and giant danio (Devario aequipinnatus) [45], such a comparison has not been carried out in mouse models. This study provides a comprehensive analysis of the labeling efficacy of the IB4, WGA, and LEA lectins in histological staining of blood vessels in brain sections and a comparison of this method with the intracardiac perfusion of the WGA lectin in labeling blood vessels in the brain and other organs. We found that among the three lectins used in this study, the LEA lectin had by far the highest efficacy in labeling blood vessels in free-floating brain sections when using histological approaches.

Our findings also underline the importance of establishing a reliable and consistent method to implement lectin use in histological staining of blood vessels. Indeed, several recently published studies relied on the IB4 lectin to stain blood vessels in embryos [46], in the retina [47-49], and also in the brain [50,51]; however, our systematic comparison showed that the LEA lectin is preferable to IB4 in such applications, particularly in the brain of adult mice.

Our study also showed that the lectin with the lowest specificity, the WGA lectin, exhibited a concentration-dependent efficacy in labeling blood vessels in the brain when intracardially injected; furthermore, the highest concentrations used in this study $(50 \mu \mathrm{g} / \mathrm{mL}$ and $125 \mu \mathrm{g} / \mathrm{mL}$ ) showed similar results to the LEA lectin histological staining in labeling blood vessels in the brain. The evidence that WGA efficacy in labeling blood vessels varies depending on the labeling method (histology on free-floating sections vs. direct labeling of the vasculature during terminal transcardial perfusion) points out that the labeling efficacy of the LEA and IB4 lectins may improve upon direct injection in the bloodstream. However, a previous study where perfusion with the LEA lectin was found to be superior to IB4 to label choroidal and retinal vasculature [52] suggests that an improved method for lectin delivery may not alter the intrinsic difference of the two lectins in labeling blood vessels that we reported in our study. An independent experiment confirmed that the labeling efficacy of intracardial perfusion with the WGA lectin at a $50 \mu \mathrm{g} / \mathrm{mL}$ concentration and the LEA lectin histological staining in labeling blood vessels in most of the other organs analyzed (dura, spinal cord, heart, kidney, muscle) is similar. The liver where the LEA lectin histological staining showed a better signal-to-noise ratio than the intracardially perfused WGA lectin represented the only exception. This result can be explained by the unique structure of blood vessels in the liver. Indeed, the liver sinusoidal endothelial cells are characterized by the presence of open pores, or "fenestrae", which enable them to control, based on their size, the molecules that can leave the sinusoidal lumen and reach the parenchymal cells [34]. Interestingly, it has been shown that several lectins, including LEA, are able to bind to the sinusoidal endothelial cells in the liver after intravitreal injection; in particular, it appears that sinusoidal endothelial cells in the liver take up lectins in vesicles that resemble, in some cases, coated vesicles of receptor-mediated endocytosis. However, 
this capability appears to happen only in vivo as it was completely abolished when the lectin was injected after fixation [53]. This finding points out the need to carefully choose the method used for blood vessel staining taking into account the structural differences that different tissues might have.

Since lectins are able to specifically recognize and bind to different carbohydrates through their carbohydrate-binding domains (see Table 1 modified from [30]; nominal carbohydrate specificity was described as in [54]), they have also been used to identify the carbohydrates on the cell surface that are important in cell-cell interactions and during development.

Table 1. Table summarizing the characteristics of the lectins used in the study; modified from the study by Jilani et al., 2003 [30]; nominal carbohydrate specificity as in the study by Goldstein and Poretz, 2012 [54].

\begin{tabular}{|c|c|c|c|}
\hline Lectin Abbreviation & Source & Carbohydrate Group & Nominal Carbohydrate Specificity \\
\hline WGA & Triticum vulgaris & N-acetylglucosammine & $\begin{array}{c}\text { GlcNAc( } \beta 1,4 \text { GlcNAc }) 1-2>\beta \text { GlcNAc }> \\
\text { Neu5Ac }\end{array}$ \\
\hline LEA & $\begin{array}{l}\text { Lycopersicon esculentum } \\
\text { (Tomato) }\end{array}$ & $\mathrm{N}$-acetylglucosammine & $\begin{array}{c}\text { GlcNAc } \beta 1,4 \mathrm{GlcNAc} \beta 1,4 \mathrm{GlcNAc} \beta 1,4 \mathrm{GlcNAc} \\
>\text { GlcNAc } \beta 1,4 \mathrm{GlcNAc} \beta 1,4 \mathrm{GlcNAc}> \\
\text { GlcNAc } \beta 1,4 \mathrm{GlcNAc}\end{array}$ \\
\hline IB4 & Griffonia (Bandeiraea) simplicifolia & $\mathrm{N}$-acetylglucosammine/ galactose & $\alpha \mathrm{GlcNAc}=\beta \mathrm{GlcNAc}$ \\
\hline
\end{tabular}

Indeed, Wearne et al. [55] used staining with 34 labeling lectins (using WGA, LEA and IB4, among the others) to establish the different carbohydrate composition of undifferentiated and differentiated human embryonic stem cells (hESCs). Furthermore, they demonstrated a lack of correlation between the specificity of the binding and the location of the staining since lectins with the same carbohydrate specificity would label hESCs differently. This observation could explain the different labeling efficacy of the lectins that we reported in this study. In our study, the WGA lectin showed a diffuse and unspecific labeling of vascular walls and the parenchyma when applied for histological labeling of brain sections; thus, our observations are in line with those of Kostrominova [56] who used the WGA lectin staining to visualize the general background in structures such as the skeletal muscle, the bone, and the ligament/tendon due to its diffuse labeling pattern. However, it should also be noted that WGA has been used since 1978 as a retrograde tracer when injected stereotaxically in the brain [57]; indeed, synaptic plasma membranes are rich in glycoproteins that are bound by WGA, among other lectins [58], and this could explain why the WGA lectin, when applied directly to the brain tissue, showed diffuse staining in our study.

The carbohydrate composition on cell membranes can change in response to an injury, infection, or pathological state, and lectin-binding patterns may change accordingly. For example, Melo-Junior et al. [59] reported that the binding of concanavalin A (Con A) and the WGA lectin to the human gastric epithelium is altered in patients affected by Helicobacter pylori infection; Cuzzocrea et al. [60] showed that the expression of intercellular adhesion molecule 1 (ICAM-1), a glycoprotein expressed by endothelial cells, is increased one hour after reperfusion in a mouse model of ischemia following splanchnic artery occlusion shock (SAO). Such changes have also been reported in hepatocarcinoma (HCC) patients where the decreased expression of C-type lectin domain family 3 member B (CLEC3B) also shows a diagnostic value [61].

In an attempt to address whether pathological conditions might induce modifications of the carbohydrate residues on endothelial cells that could lead to a different lectin binding pattern of blood vessels in the brain, we analyzed the LEA lectin labeling of blood vessels in the brain of the mice that underwent tMCAo to induce stroke. Despite an unaltered sensitivity of the LEA lectin to labeling blood vessels in the ischemic brain, its specificity was significantly decreased in the necrotic core 7 days after tMCAo, as well as in the peri-infarct region at both 1 and 7 days post-stroke. We visually observed the LEA lectin binding to elements in the brain other than blood vessels. By co-immunostaining, we verified an overlapping of the LEA lectin's signal with the microglial marker Iba1. We did not find co-staining with astrocytic GFAP. 
The previous studies reported that lectins are able to label macrophages [31], thus it is not surprising that the brain-resident macrophages, also known as the microglia, can also be labeled by lectins, and indeed Ricinus communis agglutinin 1 (RCA-1) has been widely used to stain microglia in rodent [62] and human tissues [63]. Interestingly, a study aiming to prove the beneficial effect of the umbilical cord matrix stem cells transplantation on the inflammatory response after global ischemia in a mouse model of cardiac arrest showed that RCA-1 fails to label microglia when the cardiac arrest does not occur [64], suggesting that RCA-1 may label microglia only in the event of a strong inflammatory response.

In the initial stages of ischemic stroke, microglia are known to polarize towards the M2 neuroprotective phenotype and switch later on towards the M1 neurotoxic phenotype, especially in the peri-infarct region [65]; this process induces microglia to upregulate a different set of molecules that could cause the LEA lectin to recognize microglia in the event of a strong inflammatory response, similarly to what happens to RCA-1 in the cardiac arrest rat model [64]. Furthermore, it has been reported that microglia-released cytokines interleukin $1 \alpha(\mathrm{IL}-1 \alpha)$, tumor necrosis factor $\alpha(\mathrm{TNF} \alpha)$, and the complement component subunit $1 \mathrm{q}(\mathrm{C} 1 \mathrm{q})$ are able to induce polarization of astrocytes towards the neurotoxic A1 phenotype both in vitro and in vivo [66]. As a response to those cytokines, the peri-infarct region undergoes reactive astrogliosis and forms the so-called glial scar, which limits the expansion of the necrotic area [67]. Despite the fact that activated astrocytes are known to adopt a hypertrophic morphology and upregulate GFAP and other molecules [68], they do not appear to express molecules that can be recognized by the LEA lectin as no overlap with the GFAP marker was observed in our study.

The fact that most of our studies were conducted with lectins conjugated to a 488 or FITC dye may raise concerns regarding autofluorescence phenomena. Indeed, autofluorescence of the brain tissue has already been used to assess tridimensional brain morphology and structural organization with high resolution through optical projection tomography [69]. To address whether autofluorescence could play a role in our studies, altering the LEA's signal-to-noise ratio, we tested this hypothesis using as the negative control the brain tissue that was not stained with lectins, confirming that the signal associated with the LEA lectin staining was indeed specific and not altered by autofluorescence.

Finally, lectins might present some limitations when applied for in vivo labeling of the vasculature; indeed, lectins are known to cause coagulation of red blood cells with potentially fatal consequences. Therefore, lectins are likely limited to sectioned tissues or in vivo delivery shortly before sacrificing the animal, while fluorescent dyes without specific binding capabilities are suitable for imaging over extended periods of time $[17,18]$.

In light of the topics discussed above, we want to encourage the use of the LEA lectin as a reliable marker for labeling blood vessels in immunohistochemical approaches. If the experimental design allows it, direct injection of the WGA lectin at the medium concentration $(50 \mu \mathrm{g} / \mathrm{mL})$ in the bloodstream during terminal intracardial perfusion provides results that are comparable to histochemical techniques, whilst higher doses $(125 \mu \mathrm{g} / \mathrm{mL})$ are able to produce an even better signal-to-noise ratio. Indeed, lectins show specificity towards blood vessels, as suggested by overlapping signals with GLUT-1 staining and Tie2-eGFP reporter mice. However, it has to be noted that the physiological characteristics of the tissue of interest can interfere with the binding of lectins to the carbohydrate residues on cellular surfaces such as in stroke mouse models, therefore limiting their applicability in some experimental settings.

\section{Materials and Methods}

\subsection{Animals}

Adult male C57BL/ 6 mice (12-week-old) were purchased from Janvier Laboratories and Charles Rivers (for the tMCAo studies) and were used in this study. The mice were kept in the standard laboratory conditions, with a $12 \mathrm{~h}$ dark-light cycle and ad libitum access to water and food. The experiments were conducted according to ethics permit Nos. 5.8.18-08269/2019 and 5.8.18-08160/2021 approved by the Malmö-Lund Ethics Com- 
mittee on Animal Research and Landesamt für Natur-, Umwelt- und Verbraucherschutz (81-02.04.2019.A214/01).

Tie2-eGFP mice purchased from The Jackson Laboratory (stock No. 003658) were bred in the University of Rochester vivarium and used for experiments in adult age after approval of the University of Rochester Medical Center Committee on Animal Resources.

Prox1-eGFP mice [36], back-crossed on a B6 genetic background, were kindly provided by Dr. Kari Alitalo.

\subsection{Supplies}

All the supplies, including lectins, were purchased from Sigma-Aldrich unless otherwise stated. The primary antibodies were purchased from Merck Millipore (Burlington, MA, USA; GLUT-1, cat. No. MABS132), WAKO (Richmond, VA, USA; Iba1, cat. No. 019-19741), Serotec (Oxford, UK; CD68, cat. No. MCA1957), DAKO (Agilent, Santa Clara, CA, USA; GFAP, cat. No. Z033429), and Abcam (Cambridge, UK; CD31, cat. No. ab28364; $\alpha$-SMA, cat. No. ab5694). The secondary antibodies were purchased from Invitrogen (Waltham, MA, USA). Cy3-conjugated streptavidin was purchased from Jackson ImmunoResearch (Cambridge, UK).

\subsection{Transient Middle Cerebral Artery Occlusion (tMCAo)}

The left middle cerebral artery (MCA) was occluded under isoflurane anesthesia $(70 \%$ $\mathrm{N}_{2} \mathrm{O}, 30 \% \mathrm{O}_{2}$ ). The monofilament (9-10 mm coating length, $0.19 \pm 0.01 \mathrm{~mm}$ tip diameter; Doccol, Sharon, MA, US) was inserted through microincision in the external carotid artery and further advanced to the internal carotid artery. The body temperature was maintained at $37 \pm 0.5{ }^{\circ} \mathrm{C}$ with a heating pad. The cerebral blood flow (CBF) was monitored with laser Doppler flowmetry (Moor Instruments, Axminster, Devon, United Kingdom). Reperfusion was initiated after $60 \mathrm{~min}$ by removing the filament. The mice were sacrificed 1 ( $n=5$ mice) or 7 ( $n=5$ mice) days after tMCAo.

\subsection{Neuroscore Determination in Mice after $\mathrm{MCA}$ o}

We assessed the neurological dysfunction with a neurological scoring system 1,3 , and 7 days after tMCAo [70]. The score ranges from 0 (no deficits) to 56 (poorest performance in all the items) and it is calculated as the sum of the general and focal deficits, including the following general deficits (scores): hair $(0-2)$, ears $(0-2)$, eyes $(0-4)$, posture $(0-4)$, spontaneous activity ( $0-4)$, and epileptic behavior (0-12); and the following focal deficits: body symmetry $(0-4)$, gait $(0-4)$, climbing $(0-4)$, circling behavior $(0-4)$, forelimb symmetry $(0-4)$, compulsory circling $(0-4)$, and whisker response $(0-4)$.

\subsection{Nissl Staining for Infarct Size Determination in Mice after tMCAo}

The mice were intracardially perfused with phosphate-buffered saline $(1 \times$ PBS $)$ followed by perfusion with $4 \%$ paraformaldehyde (4\% PFA) for fixation of the tissues 1 or 7 days after tMCAo. Brains were harvested and post-fixed overnight in 4\% PFA before they were sectioned with a vibratome $(100 \mu \mathrm{m}$ thickness). Every $300 \mu \mathrm{m}$, a $20 \mu \mathrm{m}$ section was collected to perform Nissl staining for infarct size determination. Briefly, the selected sections were mounted on a slide and allowed to dry before they were washed in $\mathrm{dH}_{2} \mathrm{O}$ to remove residual salts. To stain the sections at $60^{\circ} \mathrm{C}, 0.1 \%$ cresyl violet solution (filtered and preheated; Carl Roth, Karlsruhe, Germany) was used. After washing the sections in $\mathrm{dH}_{2} \mathrm{O}$ to remove the excess stain, they were dehydrated through immersion to the increasing concentrations of ethanol. Finally, the sections were immersed in xylene and covered using Eukitt (Orsatec $\mathrm{GmbH}$, Bobingen, Germany). Infarct size was determined from Nissl-stained brain sections using the ImageJ software $(\mathrm{NIH}$, version $2.0 .0-\mathrm{rc}-31 / 1.49 \mathrm{v}$; $\mathrm{U}$. S. National Institutes of Health, Bethesda, MD, US). The areas were integrated to calculate the infarct volume. In order to correct for tissue swelling, the infarct volume was expressed as the percentage of the non-infarcted (contralateral) hemisphere. 
4.6. Histological Labeling of Coronal Tissue Sections of C57BL/6 Mice with the IB4, LEA, and WGA Lectins

The C57BL/ 6 mice $(n=6)$ were anesthetized with a ketamine-xylazine mix (ketamine, $100 \mathrm{mg} / \mathrm{kg}$; xylazine, $20 \mathrm{mg} / \mathrm{kg})$ perfused with phosphate-buffered saline $(1 \times \mathrm{PBS})$ followed by a perfusion with $4 \%$ PFA for fixation of the tissues. The brain, skeletal muscles, the heart, the kidney, and the liver were harvested and post-fixed overnight in $4 \%$ PFA before they were sliced with a vibratome (100 $\mu \mathrm{m}$ thickness). The vertebral column containing the spinal cord was also harvested and post-fixed overnight in 4\% PFA before the spinal cord was dissected and processed like the other harvested tissues. The skull cap containing the dura mater was also collected and post-fixed overnight in 4\% PFA, followed by dissection. Solutions of the IB4 (Sigma-Aldrich, Burlington, MA, US; lyophilized, cat. No. L2895), LEA-488 (ThermoFisher Scientific, Waltham, MA, U.S; cat. No. L32470), or LEA-649 (Vector Lab, Burlingame, CA, US; cat. No. DL-1178-1) and WGA-FITC (lyophilized, cat. No. L4895) lectins were prepared at concentrations of $5 \mu \mathrm{g} / \mathrm{mL}, 10 \mu \mathrm{g} / \mathrm{mL}$, and $20 \mu \mathrm{g} / \mathrm{mL}$ and used to histochemically stain coronal sections of the organs and the whole-mount dura mater for one hour before the sections were washed three times with $1 \times$ PBS and mounted for imaging.

\subsection{WGA Lectin Perfusion of C57BL/6 Mice}

Lyophilized WGA lectin powder was diluted with $1 \times$ PBS in three solutions at the concentrations of $5 \mu \mathrm{g} / \mathrm{mL}, 50 \mu \mathrm{g} / \mathrm{mL}$, and $125 \mu \mathrm{g} / \mathrm{mL}$, respectively. The C57BL/ 6 mice were anesthetized with a single intraperitoneal injection of the ketamine-xylazine mix (ketamine, $100 \mathrm{mg} / \mathrm{kg}$; xylazine, $20 \mathrm{mg} / \mathrm{kg}$ ) and then intracardially perfused with $1 \times$ PBS. Immediately after that, $5 \mathrm{~mL}$ of the WGA lectin solution were injected during the perfusion and allowed to bind to blood vessels for two minutes before further perfusion with $4 \%$ PFA for fixation of the tissues. The organs were harvested and post-fixed overnight in $4 \%$ PFA before they were sliced with a vibratome (100 $\mu \mathrm{m}$ thickness) and mounted on glass slides for imaging; $n=3$ mice for the $5 \mu \mathrm{g} / \mathrm{mL}$ group, $n=7$ mice for the $50 \mu \mathrm{g} / \mathrm{mL}$ group, $n=5$ mice for the $125 \mu \mathrm{g} / \mathrm{mL}$ group.

\subsection{GLUT-1, Iba1, CD68, GFAP, CD31, $\alpha$-SMA Immunostaining, and Biotin Revelation}

Tie2-eGFP reporter mice $(n=4)$ were used in order to assess the specificity of lectin labeling of blood vessels. Briefly, the Tie2-eGFP reporter mice were intravenously injected with biotinylated lectin $(125 \mu \mathrm{g} / \mathrm{mL})$ and intracardially perfused with $1 \times$ PBS and $4 \%$ PFA thereafter. Brain sections obtained from the Tie2-eGFP reporter mice were histochemically stained with Cy3-conjugated streptavidin and the GLUT-1 antibody. Briefly, a blocking solution ( $0.5 \%$ Triton X-100 and 5\% serum) was applied for one hour at room temperature (RT) to minimize unspecific antibody binding. Then, the primary antibody $\alpha$-GLUT- 1 (mouse, concentration 1:250) was allowed to label the tissue overnight at $4{ }^{\circ} \mathrm{C}$ under gentle shaking. The day after that, the sections were rinsed three times with $1 \times$ PBS before the secondary antibody (Cy5 anti-mouse, 1:500) and Cy3-conjugated streptavidin (1:500) were allowed to label the brain sections for $90 \mathrm{~min}$ at RT under gentle shaking. Following three rinses with $1 \times$ PBS, 4',6-diamidin-2-fenilindolo (DAPI, 1:1000) was applied before the sections were mounted.

GLUT-1 immunostaining was also used to assess lectin labeling specificity in the mice after tMCAo. Coronal brain sections of the tMCAo and naïve mice were stained using the same procedure as described above with the exception that no biotin revelation was performed, and instead the sections were incubated for $1 \mathrm{~h}$ at RT with a solution of the FITC-labeled LEA lectin $(5 \mu \mathrm{g} / \mathrm{mL}$, concentrated) after the secondary antibody incubation and before the DAPI incubation. Co-labeling with the GFAP (rabbit, concentration 1:500) and Iba1 (rabbit, concentration 1:250) primary antibodies was performed in some samples to immunolabel astrocytes and microglia.

CD31 and $\alpha$-SMA immunostaining was used to assess lectin co-labeling in coronal sections of the brain, kidney, and spleen of wild-type mice. The abovementioned procedure 
was used for the staining, with the following exceptions for the CD31 staining: (i) the sections were preincubated in a sodium citrate buffer ( $\mathrm{pH}$ 6.0) to allow antigen retrieval; (ii) a blocking solution ( $0.3 \%$ Triton $\mathrm{X}-100,5 \%$ BSA, and 1\% serum) was also used for primary antibody incubation.

\subsection{Image Acquisition and Analysis}

Mounted organ sections and the whole-mount dura mater were imaged using a confocal scanning microscope (Nikon A1RHD) at $10 \times$ magnification for whole section visualization and $20 \times$ Nyquist magnification for detailed imaging of the stained blood vessels. The acquired confocal images were analyzed using the Fiji software (NIH, version 2.0.0-rc-69/1.53c). Specifically, the labeling efficacy of the lectins used for histological staining as well as intracardial perfusion was calculated as the ratio of the averaged peak signal at the vascular walls to the background signal (signal-to-noise ratio) obtained by drawing a cross-section of the vessels using the line plot tool in Fiji [71].

For the analysis of the number of vessels $/ \mathrm{mm}^{2}$, the vessels were counted manually in each image (three acquisitions/animal); for the analysis of the percentage of the area over the threshold, the Fiji software was used to set a manual threshold for each image ( 3 acquisitions/animal), and the area covered by the stained vessels over the total area was automatically calculated by the software.

For the co-localization analysis of the LEA lectin and GLUT-1 staining, Tie2-labeled vessels were identified and the presence of lectin and GLUT-1 staining in each Tie2-labeled vessel was assessed as 1 (stained) or 0 (non-stained) (six vessels/animal). The same analysis was used to assess the co-localization of the LEA lectin with CD31 and $\alpha$-SMA staining, with the exception that in this case blood vessels were identified by CD31 or $\alpha$-SMA labeling.

The LEA lectin's specificity in infarcted brains was calculated as the percentage of the difference between the total number of elements labeled by the lectin and the number of blood vessels identified by the positivity to GLUT-1 immunostaining in each image (three acquisitions/animal).

Three-dimensional reconstructions and volumetric projections were generated using the Arivis Vision4D software.

\subsection{Statistical Analysis}

All the statistical testing was performed in GraphPad Prism 9 (GraphPad Software; San Diego, CA, US). The Shapiro-Wilk test was used to test the normal distribution of the data. Two groups were compared using unpaired Student's $t$-test and Welch's $t$-test or paired Student's $t$-test according to the experimental design; the nonparametric MannWhitney $U$ test was used when the unpaired data followed non-normal distribution, and the nonparametric Wilcoxon test was used when the paired data followed non-normal distribution. For comparison of more than two groups, one-way ANOVA followed by Tukey's multiple comparisons post hoc test was used. To compare the differences between the intact hemisphere and the infarcted hemisphere between the naïve and tMCAo mice, a two-way ANOVA followed by Tukey's and Sidak's multiple comparisons post hoc tests was performed.

All the values are expressed as the means \pm SEM; $n$ represents the number of animals; $p<0.05$ was accepted as statistically significant.

Supplementary Materials: The following are available online at https:/ / www.mdpi.com/article / 10.3390/ijms222111554/s1, Figure S1: Comparison of the LEA lectin labeling of longitudinally vs. coronally sectioned vessels; Figure S2: Determination of lectin labeling of veins vs. arteries vs. lymphatic vessels; Figure S3: LEA lectin's specificity in the penumbra of mice after tMCAo; Supplementary Movie1: Volumetric projection of a lymphatic vessel in the dura of a Prox1-eGFP mouse labeled with the LEA lectin conjugated to AlexaFluor-647. 
Author Contributions: Conceptualization, R.B., A.M. and I.L.; Data curation, R.B., M.K., H.M., A.M. and I.L.; Formal analysis, R.B., M.K., H.M., A.M. and I.L.; Funding acquisition, A.M., M.N. and I.L.; Investigation, R.B., M.K., H.M., A.M. and and I.L.; Methodology, R.B., M.K., H.M., D.H. and and A.X.C.; Project administration, I.L.; Resources, A.M., M.N. and I.L.; Supervision, R.B., A.M. and I.L.; Validation, R.B.; Visualization, R.B. and I.L.; Writing—original draft preparation, R.B., A.M. and I.L.; Writing-review and editing, R.B., M.K., H.M., D.H., A.X.C., A.M., M.N. and I.L. All authors have read and agreed to the published version of the manuscript.

Funding: This work was funded by the Knut and Alice Wallenberg Foundation (F2015/2112; I.L.), Åhlén Foundation (193082, 203102; I.L.), Swedish Research Council (VR; 2017-01243; A.M.); German Research Foundation (DFG; ME 4667/2-1; A.M.); Sparbanken Stiftelse (A.M.); Strokeriksförbundet (A.M.); Hjärnfonden (FO2021-0112; A.M.); Hedlund Stiftelse (M-2019-1101; A.M.), and the Swedish Parkinson Research Foundation (I.L.).

Institutional Review Board Statement: The study was conducted according to the guidelines of the Declaration of Helsinki and approved by the Malmö-Lund Ethics Committee on Animal Research (protocol Nos. 5.8.18-08269/2019 and 5.8.18-08160/2021), by Landesamt für Natur-, Umwelt- und Verbraucherschutz NRW (protocol No. 81-02.04.2019.A214/01), and by the University of Rochester Medical Center Committee on Animal Resources.

Informed Consent Statement: Not applicable.

Data Availability Statement: All the data generated or analyzed during this study are included in this published article and the Supplementary Materials.

Acknowledgments: Lund University Bioimaging Centre (LBIC) is gratefully acknowledged for providing experimental resources. Jong Suk Kim, Nyrie Soukiazian, and Ezra Yang are acknowledged for technical assistance. We thank Kari Alitalo for kindly providing Prox1-eGFP mice.

Conflicts of Interest: The authors declare no conflict of interest.

\section{References}

1. Aird, W.C. Discovery of the cardiovascular system: From Galen to William Harvey. J. Thromb. Haemost. $2011,9,118-129$. [CrossRef] [PubMed]

2. Risau, W. Mechanisms of angiogenesis. Nature 1997, 386, 671-674. [CrossRef]

3. Brown, W.R.; Thore, C.R. Review: Cerebral microvascular pathology in ageing and neurodegeneration. Neuropathol. Appl. Neurobiol. 2011, 37, 56-74. [CrossRef]

4. Boero, J.A.; Ascher, J.; Arregui, A.; Rovainen, C.; Woolsey, T.A. Increased brain capillaries in chronic hypoxia. J. Appl. Physiol. 1999, 86, 1211-1219. [CrossRef]

5. He, Q.W.; Li, Q.; Jin, H.J.; Zhi, F.; Suraj, B.; Zhu, Y.Y.; Xia, Y.P.; Mao, L.; Chen, X.L.; Hu, B. MiR-150 Regulates Poststroke Cerebral Angiogenesis via Vascular Endothelial Growth Factor in Rats. CNS Neurosci. Ther. 2016, 22, 507-517. [CrossRef] [PubMed]

6. Hayward, N.M.; Immonen, R.; Tuunanen, P.I.; Ndode-Ekane, X.E.; Grohn, O.; Pitkanen, A. Association of chronic vascular changes with functional outcome after traumatic brain injury in rats. J. Neurotrauma 2010, 27, 2203-2219. [CrossRef] [PubMed]

7. Barcia, C.; Bautista, V.; Sanchez-Bahillo, A.; Fernandez-Villalba, E.; Faucheux, B.; Poza y Poza, M.; Barreiro, A.F.; Hirsch, E.C.; Herrero, M.T. Changes in vascularization in substantia nigra pars compacta of monkeys rendered parkinsonian. J. Neural Transm. 2005, 112, 1237-1248. [CrossRef] [PubMed]

8. Ohlin, K.E.; Francardo, V.; Lindgren, H.S.; Sillivan, S.E.; O'Sullivan, S.S.; Luksik, A.S.; Vassoler, F.M.; Lees, A.J.; Konradi, C.; Cenci, M.A. Vascular endothelial growth factor is upregulated by L-dopa in the parkinsonian brain: Implications for the development of dyskinesia. Brain 2011, 134, 2339-2357. [CrossRef] [PubMed]

9. Black, J.E.; Polinsky, M.; Greenough, W.T. Progressive failure of cerebral angiogenesis supporting neural plasticity in aging rats. Neurobiol. Aging 1989, 10, 353-358. [CrossRef]

10. Hase, Y.; Ding, R.; Harrison, G.; Hawthorne, E.; King, A.; Gettings, S.; Platten, C.; Stevenson, W.; Craggs, L.J.L.; Kalaria, R.N. White matter capillaries in vascular and neurodegenerative dementias. Acta Neuropathol. Commun. 2019, 7, 16. [CrossRef] [PubMed]

11. Muller, A.M.; Hermanns, M.I.; Skrzynski, C.; Nesslinger, M.; Muller, K.M.; Kirkpatrick, C.J. Expression of the endothelial markers PECAM-1, vWf, and CD34 in vivo and in vitro. Exp. Mol. Pathol. 2002, 72, 221-229. [CrossRef]

12. Bell, R.D.; Winkler, E.A.; Sagare, A.P.; Singh, I.; LaRue, B.; Deane, R.; Zlokovic, B.V. Pericytes control key neurovascular functions and neuronal phenotype in the adult brain and during brain aging. Neuron 2010, 68, 409-427. [CrossRef] [PubMed]

13. Koonce, N.A.; Griffin, R.J.; Dings, R.P.M. Galectin-1 Inhibitor OTX008 Induces Tumor Vessel Normalization and Tumor Growth Inhibition in Human Head and Neck Squamous Cell Carcinoma Models. Int. J. Mol. Sci. 2017, 18, 2671. [CrossRef] [PubMed]

14. Eriksdotter-Nilsson, M.; Bjorklund, H.; Olson, L. Laminin immunohistochemistry: A simple method to visualize and quantitate vascular structures in the mammalian brain. J. Neurosci. Methods 1986, 17, 275-286. [CrossRef] 
15. Walchli, T.; Mateos, J.M.; Weinman, O.; Babic, D.; Regli, L.; Hoerstrup, S.P.; Gerhardt, H.; Schwab, M.E.; Vogel, J. Quantitative assessment of angiogenesis, perfused blood vessels and endothelial tip cells in the postnatal mouse brain. Nat. Protoc. 2015, 10, 53-74. [CrossRef] [PubMed]

16. Honkura, N.; Richards, M.; Lavina, B.; Sainz-Jaspeado, M.; Betsholtz, C.; Claesson-Welsh, L. Intravital imaging-based analysis tools for vessel identification and assessment of concurrent dynamic vascular events. Nat. Commun. 2018, 9, 2746. [CrossRef] [PubMed]

17. Iliff, J.J.; Wang, M.; Zeppenfeld, D.M.; Venkataraman, A.; Plog, B.A.; Liao, Y.; Deane, R.; Nedergaard, M. Cerebral arterial pulsation drives paravascular CSF-interstitial fluid exchange in the murine brain. J. Neurosci. 2013, 33, 18190-18199. [CrossRef] [PubMed]

18. Mestre, H.; Tithof, J.; Du, T.; Song, W.; Peng, W.; Sweeney, A.M.; Olveda, G.; Thomas, J.H.; Nedergaard, M.; Kelley, D.H. Flow of cerebrospinal fluid is driven by arterial pulsations and is reduced in hypertension. Nat. Commun. 2018, 9, 4878. [CrossRef]

19. Steinman, J.; Koletar, M.M.; Stefanovic, B.; Sled, J.G. 3D morphological analysis of the mouse cerebral vasculature: Comparison of in vivo and ex vivo methods. PLoS ONE 2017, 12, e0186676. [CrossRef] [PubMed]

20. Schaad, L.; Hlushchuk, R.; Barre, S.; Gianni-Barrera, R.; Haberthur, D.; Banfi, A.; Djonov, V. Correlative Imaging of the Murine Hind Limb Vasculature and Muscle Tissue by MicroCT and Light Microscopy. Sci. Rep. 2017, 7, 41842. [CrossRef] [PubMed]

21. Mazzetti, S.; Frigerio, S.; Gelati, M.; Salmaggi, A.; Vitellaro-Zuccarello, L. Lycopersicon esculentum lectin: An effective and versatile endothelial marker of normal and tumoral blood vessels in the central nervous system. Eur. J. Histochem. 2004, 48, 423-428. [CrossRef] [PubMed]

22. Sorriento, D.; Campanile, A.; Santulli, G.; Leggiero, E.; Pastore, L.; Trimarco, B.; Iaccarino, G. A new synthetic protein, TAT-RH, inhibits tumor growth through the regulation of NFkappaB activity. Mol. Cancer 2009, 8, 97. [CrossRef] [PubMed]

23. Santulli, G.; Basilicata, M.F.; De Simone, M.; Del Giudice, C.; Anastasio, A.; Sorriento, D.; Saviano, M.; Del Gatto, A.; Trimarco, B.; Pedone, C.; et al. Evaluation of the anti-angiogenic properties of the new selective alphaVbeta3 integrin antagonist RGDechiHCit. J. Transl. Med. 2011, 9, 7. [CrossRef] [PubMed]

24. Robertson, R.T.; Levine, S.T.; Haynes, S.M.; Gutierrez, P.; Baratta, J.L.; Tan, Z.; Longmuir, K.J. Use of labeled tomato lectin for imaging vasculature structures. Histochem. Cell Biol. 2015, 143, 225-234. [CrossRef]

25. Chen, H.; Fu, X.; Jiang, J.; Han, S. C16 Peptide Promotes Vascular Growth and Reduces Inflammation in a Neuromyelitis Optica Model. Front. Pharmacol. 2019, 10, 1373. [CrossRef] [PubMed]

26. Bryson, J.L.; Coles, M.C.; Manley, N.R. A method for labeling vasculature in embryonic mice. J. Vis. Exp. 2011, 56, 3267. [CrossRef] [PubMed]

27. Simionescu, M.; Simionescu, N.; Palade, G.E. Differentiated microdomains on the luminal surface of capillary endothelium: Distribution of lectin receptors. J. Cell Biol. 1982, 94, 406-413. [CrossRef] [PubMed]

28. Minamikawa, T.; Miyake, T.; Takamatsu, T.; Fujita, S. A new method of lectin histochemistry for the study of brain angiogenesis. Lectin angiography. Histochemistry 1987, 87, 317-320. [CrossRef] [PubMed]

29. Todorov, M.I.; Paetzold, J.C.; Schoppe, O.; Tetteh, G.; Shit, S.; Efremov, V.; Todorov-Volgyi, K.; During, M.; Dichgans, M.; Piraud, M.; et al. Machine learning analysis of whole mouse brain vasculature. Nat. Methods 2020, 17, 442-449. [CrossRef]

30. Jilani, S.M.; Murphy, T.J.; Thai, S.N.; Eichmann, A.; Alva, J.A.; Iruela-Arispe, M.L. Selective binding of lectins to embryonic chicken vasculature. J. Histochem. Cytochem. 2003, 51, 597-604. [CrossRef]

31. Dullmann, J.; Van Damme, E.J.; Peumans, W.J.; Ziesenitz, M.; Schumacher, U. Lectin histochemistry of the rat lymph node: Visualisation of stroma, blood vessels, sinuses, and macrophages. A contribution to the concept of an immune accessory role of sinus-lining endothelia. Acta Histochem. 2002, 104, 77-83. [CrossRef] [PubMed]

32. Fu, Y.Y.; Peng, S.J.; Lin, H.Y.; Pasricha, P.J.; Tang, S.C. 3-D imaging and illustration of mouse intestinal neurovascular complex. Am. J. Physiol.-Gastrointest. Liver Physiol. 2013, 304, G1-G11. [CrossRef] [PubMed]

33. Nag, S. Ultrastructural localization of lectin receptors on cerebral endothelium. Acta Neuropathol. 1985, 66, 105-110. [CrossRef] [PubMed]

34. Braet, F.; Wisse, E. Structural and functional aspects of liver sinusoidal endothelial cell fenestrae: A review. Comp. Hepatol. 2002, 1, 1. [CrossRef] [PubMed]

35. Quaggin, S.E.; Kreidberg, J.A. Development of the renal glomerulus: Good neighbors and good fences. Development 2008, 135, 609-620. [CrossRef] [PubMed]

36. Choi, I.; Chung, H.K.; Ramu, S.; Lee, H.N.; Kim, K.E.; Lee, S.; Yoo, J.; Choi, D.; Lee, Y.S.; Aguilar, B.; et al. Visualization of lymphatic vessels by Prox1-promoter directed GFP reporter in a bacterial artificial chromosome-based transgenic mouse. Blood 2011, 117, 362-365. [CrossRef] [PubMed]

37. Leino, R.L.; Gerhart, D.Z.; van Bueren, A.M.; McCall, A.L.; Drewes, L.R. Ultrastructural localization of GLUT 1 and GLUT 3 glucose transporters in rat brain. J. Neurosci. Res. 1997, 49, 617-626. [CrossRef]

38. Dumont, D.J.; Yamaguchi, T.P.; Conlon, R.A.; Rossant, J.; Breitman, M.L. Tek, a novel tyrosine kinase gene located on mouse chromosome 4, is expressed in endothelial cells and their presumptive precursors. Oncogene 1992, 7, 1471-1480. [PubMed]

39. Motoike, T.; Loughna, S.; Perens, E.; Roman, B.L.; Liao, W.; Chau, T.C.; Richardson, C.D.; Kawate, T.; Kuno, J.; Weinstein, B.M.; et al. Universal GFP reporter for the study of vascular development. Genesis 2000, 28, 75-81. [CrossRef]

40. Dullmann, J.; Feldhaus, S.; Van Damme, E.J.; Peumans, W.J.; Schumacher, U. Lectin histochemistry of the spleen: A new lectin visualizes the stromal architecture of white pulp and the sinuses of red pulp. J. Histochem. Cytochem. 2000, 48, 923-931. [CrossRef] 
41. Nitzsche, A.; Poittevin, M.; Benarab, A.; Bonnin, P.; Faraco, G.; Uchida, H.; Favre, J.; Garcia-Bonilla, L.; Garcia, M.C.L.; Leger, P.L.; et al. Endothelial S1P1 Signaling Counteracts Infarct Expansion in Ischemic Stroke. Circ. Res. 2021, 128, 363-382. [CrossRef] [PubMed]

42. Swendeman, S.L.; Xiong, Y.; Cantalupo, A.; Yuan, H.; Burg, N.; Hisano, Y.; Cartier, A.; Liu, C.H.; Engelbrecht, E.; Blaho, V.; et al. An engineered S1P chaperone attenuates hypertension and ischemic injury. Sci. Signal. 2017, 10. [CrossRef]

43. Iadecola, C.; Anrather, J. The immunology of stroke: From mechanisms to translation. Nat. Med. 2011, 17, 796-808. [CrossRef] [PubMed]

44. Xu, S.; Lu, J.; Shao, A.; Zhang, J.H.; Zhang, J. Glial Cells: Role of the Immune Response in Ischemic Stroke. Front. Immunol. 2020, 11, 294. [CrossRef] [PubMed]

45. Manalo, T.; May, A.; Quinn, J.; Lafontant, D.S.; Shifatu, O.; He, W.; Gonzalez-Rosa, J.M.; Burns, G.C.; Burns, C.E.; Burns, A.R.; et al. Differential Lectin Binding Patterns Identify Distinct Heart Regions in Giant Danio ( Devario aequipinnatus) and Zebrafish (Danio rerio) Hearts. J. Histochem. Cytochem. 2016, 64, 687-714. [CrossRef] [PubMed]

46. Tan, X.; Liu, W.A.; Zhang, X.J.; Shi, W.; Ren, S.Q.; Li, Z.; Brown, K.N.; Shi, S.H. Vascular Influence on Ventral Telencephalic Progenitors and Neocortical Interneuron Production. Dev. Cell 2016, 36, 624-638. [CrossRef] [PubMed]

47. Birdsey, G.M.; Shah, A.V.; Dufton, N.; Reynolds, L.E.; Osuna Almagro, L.; Yang, Y.; Aspalter, I.M.; Khan, S.T.; Mason, J.C.; Dejana, E.; et al. The endothelial transcription factor ERG promotes vascular stability and growth through Wnt/beta-catenin signaling. Dev. Cell 2015, 32, 82-96. [CrossRef]

48. Benedito, R.; Rocha, S.F.; Woeste, M.; Zamykal, M.; Radtke, F.; Casanovas, O.; Duarte, A.; Pytowski, B.; Adams, R.H. Notchdependent VEGFR3 upregulation allows angiogenesis without VEGF-VEGFR2 signalling. Nature 2012, 484, 110-114. [CrossRef] [PubMed]

49. Poulet, M.; Sirois, J.; Boye, K.; Uetani, N.; Hardy, S.; Daubon, T.; Dubrac, A.; Tremblay, M.L.; Bikfalvi, A. PRL-2 phosphatase is required for vascular morphogenesis and angiogenic signaling. Commun. Biol. 2020, 3, 603. [CrossRef]

50. Quan, W.; Luo, Q.; Tang, Q.; Furihata, T.; Li, D.; Fassbender, K.; Liu, Y. NLRP3 Is Involved in the Maintenance of Cerebral Pericytes. Front. Cell Neurosci. 2020, 14, 276. [CrossRef] [PubMed]

51. Coucha, M.; Barrett, A.C.; Elgebaly, M.; Ergul, A.; Abdelsaid, M. Inhibition of Ephrin-B2 in brain pericytes decreases cerebral pathological neovascularization in diabetic rats. PLoS ONE 2019, 14, e0210523. [CrossRef] [PubMed]

52. Jiao, C.; Adler, K.; Liu, X.; Sun, W.; Mullins, R.F.; Sohn, E.H. Visualization of Mouse Choroidal and Retinal Vasculature Using Fluorescent Tomato Lectin Perfusion. Transl. Vis. Sci. Technol. 2020, 9, 1. [CrossRef] [PubMed]

53. Nakamura-Ishizu, A.; Morikawa, S.; Shimizu, K.; Ezaki, T. Characterization of sinusoidal endothelial cells of the liver and bone marrow using an intravital lectin injection method. J. Mol. Histol. 2008, 39, 471-479. [CrossRef] [PubMed]

54. Goldstein, I.; Poretz, R.D. Isolation, physicochemical characterization, and carbohydrate—binding specificity of Iectins. In The Lectins. Properties, Functions, and Applications in Biology and Medicine; Academic Press: Cambridge, MA, USA, 2012 ; pp. $233-247$.

55. Wearne, K.A.; Winter, H.C.; O'Shea, K.; Goldstein, I.J. Use of lectins for probing differentiated human embryonic stem cells for carbohydrates. Glycobiology 2006, 16, 981-990. [CrossRef] [PubMed]

56. Kostrominova, T.Y. Application of WGA lectin staining for visualization of the connective tissue in skeletal muscle, bone, and ligament/tendon studies. Microsc. Res. Tech. 2011, 74, 18-22. [CrossRef]

57. Schwab, M.E.; Javoy-Agid, F.; Agid, Y. Labeled wheat germ agglutinin (WGA) as a new, highly sensitive retrograde tracer in the rat brain hippocampal system. Brain Res. 1978, 152, 145-150. [CrossRef]

58. Gurd, J.W. Synaptic plasma membrane glycoproteins: Molecular identification of lectin receptors. Biochemistry 1977, 16, 369-374. [CrossRef]

59. Melo-Junior, M.R.; Cavalcanti, C.L.; Pontes-Filho, N.T.; Carvalho, L.B., Jr.; Beltrao, E.I. Lectin staining patterns in human gastric mucosae with and without exposure to Helicobacter pylori. Braz. J. Microbiol. 2008, 39, 238-240. [CrossRef] [PubMed]

60. Cuzzocrea, S.; Mazzon, E.; Costantino, G.; Serraino, I.; De Sarro, A.; Caputi, A.P. Effects of n-acetylcysteine in a rat model of ischemia and reperfusion injury. Cardiovasc. Res. 2000, 47, 537-548. [CrossRef]

61. Dai, W.; Wang, Y.; Yang, T.; Wang, J.; Wu, W.; Gu, J. Downregulation of exosomal CLEC3B in hepatocellular carcinoma promotes metastasis and angiogenesis via AMPK and VEGF signals. Cell Commun. Signal. 2019, 17, 113. [CrossRef] [PubMed]

62. Hauke, C.; Korr, H. RCA-I lectin histochemistry after trypsinisation enables the identification of microglial cells in thin paraffin sections of the mouse brain. J. Neurosci. Methods 1993, 50, 273-277. [CrossRef]

63. Andjelkovic, A.V.; Nikolic, B.; Pachter, J.S.; Zecevic, N. Macrophages/microglial cells in human central nervous system during development: An immunohistochemical study. Brain Res. 1998, 814, 13-25. [CrossRef]

64. Hirko, A.C.; Dallasen, R.; Jomura, S.; Xu, Y. Modulation of inflammatory responses after global ischemia by transplanted umbilical cord matrix stem cells. Stem Cells 2008, 26, 2893-2901. [CrossRef] [PubMed]

65. Hu, X.; Li, P.; Guo, Y.; Wang, H.; Leak, R.K.; Chen, S.; Gao, Y.; Chen, J. Microglia/macrophage polarization dynamics reveal novel mechanism of injury expansion after focal cerebral ischemia. Stroke 2012, 43, 3063-3070. [CrossRef]

66. Liddelow, S.A.; Guttenplan, K.A.; Clarke, L.E.; Bennett, F.C.; Bohlen, C.J.; Schirmer, L.; Bennett, M.L.; Munch, A.E.; Chung, W.S.; Peterson, T.C.; et al. Neurotoxic reactive astrocytes are induced by activated microglia. Nature 2017, 541, 481-487. [CrossRef]

67. Choudhury, G.R.; Ding, S. Reactive astrocytes and therapeutic potential in focal ischemic stroke. Neurobiol. Dis. 2016, 85, 234-244. [CrossRef] [PubMed] 
68. Rakers, C.; Schleif, M.; Blank, N.; Matuskova, H.; Ulas, T.; Handler, K.; Torres, S.V.; Schumacher, T.; Tai, K.; Schultze, J.L.; et al. Stroke target identification guided by astrocyte transcriptome analysis. Glia 2019, 67, 619-633. [CrossRef] [PubMed]

69. Gleave, J.A.; Wong, M.D.; Dazai, J.; Altaf, M.; Henkelman, R.M.; Lerch, J.P.; Nieman, B.J. Neuroanatomical phenotyping of the mouse brain with three-dimensional autofluorescence imaging. Physiol. Genomics 2012, 44, 778-785. [CrossRef] [PubMed]

70. Orsini, F.; Villa, P.; Parrella, S.; Zangari, R.; Zanier, E.R.; Gesuete, R.; Stravalaci, M.; Fumagalli, S.; Ottria, R.; Reina, J.J.; et al. Targeting mannose-binding lectin confers long-lasting protection with a surprisingly wide therapeutic window in cerebral ischemia. Circulation 2012, 126, 1484-1494. [CrossRef] [PubMed]

71. Schindelin, J.; Arganda-Carreras, I.; Frise, E.; Kaynig, V.; Longair, M.; Pietzsch, T.; Preibisch, S.; Rueden, C.; Saalfeld, S.; Schmid, B.; et al. Fiji: An open-source platform for biological-image analysis. Nat Methods 2012, 9, 676-682. [CrossRef] 